\title{
Disseminated intravascular coagulation and head injury
}

\author{
CH. J. VECHT, C. TH. SMIT SIBINGA, AND J. M. MINDERHOUD \\ From the Department of Neurology and the Coagulation Laboratory, \\ Department of Internal Medicine, University Hospital, Groningen, Holland
}

SYNOPSIS Blood coagulation tests were performed on admission to the hospital and on consecutive days after severe and moderate head injury in 34 patients. Platelet counts and fibrinogen were normal at admission and raised thereafter. The partial thromboplastin time was shortened at admission and lengthened in the following days. Fibrinolytic activity was enhanced at admission. The ethanol gelation test was negative in all patients during the post-traumatic time course. It was concluded that, in the first 24 hours after injury, activated coagulation was present after head injury. In contrast with data of other authors, disseminated intravascular coagulation did not occur in these series.

Recently several reports have been published about disseminated intravascular coagulation (DIC) in relation to brain injury. Preston et al. (1974) described three cases, of whom two were due to moderate head injury. Vardi et al. (1974) associated DIC with a brain tumour. Defibrination has been reported by Goodnight et al. (1974) in a series of brain injured patients.

Disseminated intravascular coagulation can be triggered by infusion of thromboplastic material. Tissue thromboplastin is released into the blood stream on disintegration of cells by, for example, trauma, operations, necrosis, and anoxia. Bang and McDowell (1966) suggest that thromboplastic material from the brain is present in the systemic circulation after cerebral infarction.

The purpose of this study is to investigate whether DIC is related to head injury. A preliminary report has already been published (Vecht and Smit Sibinga, 1974).

\section{METHODS}

The study included 34 head injured patients who were divided into three groups:

GROUP I Eight patients who all died within 24 hours after admission because of massive brain injury. Six patients had skull fracture (vault and/or base); in six

Accepted 14 January 1975) patients fractures elsewhere were present, of whom three also had a fracture of the femur. Shock was present in three patients before blood was drawn for coagulation tests.

GROUP II Seventeen patients sustained severe head injury and all remained deeply unconscious for more than four days. Eleven patients had skull fracture (vault and/or base); eight patients had fractures elsewhere, of whom three also had a fracture of the femur. Four patients died after four, seven, and eight weeks and six months respectively. One patient remained in a post-traumatic akinetic mutism.

GROUP III Nine patients sustained moderate head injury with slightly impaired consciousness. Five patients had skull fracture (vault and/or base). Four patients had fractures elsewhere.

Blood was taken for coagulation studies: (1) immediately after admission to the hospital (about two hours after injury: traffic accidents); (2) daily for the next five days; (3) on day 9 and weekly thereafter up to the sixth week after trauma (if the patient were still hospitalized).

LABORATORY METHODS Blood for coagulation studies was collected mainly by venepuncture in disposable syringes and siliconized disposable needles were used. The blood was immediately mixed with 0.1 volume of $3.06 \%$ trisodium citrate dihydrate. Platelet poor plasma was used for fibrin formation and fibrinolytic studies by the following techniques: 
FIBRIN FORMATION One-stage prothrombin time (PT) (Quick, 1966); kaolin-activated partial thromboplastin time (PTT) (Proctor and Rapaport, 1961); thrombin time (Vermylen and Verstraete, 1961); factor V assay (Stormorken, 1957); factor VIII assay, (Hardisty and MacPherson, 1962); fibrinogen (LeClerc and Khodabandeh, 1953).

FIBRINOLYSIS Twenty-four hours plasma clotlysis (Fontein, 1971); ethanol gelation test (Godal and Abildgaard, 1966), serum fibrin degeneration products (FDP); TRCHII assay (Merskey et al., 1966). As a standard laboratory routine, haemoglobin, haematocrit and platelet counts were done.

\section{RESULTS}

In group I (the deceased patients) platelet counts were almost normal at admission (Table 1). The prothrombin time was normal to slightly prolonged. The partial thromboplastin time was shortened in five of the eight patients at admission. The thrombin time was normal to slightly prolonged. Factor V levels were low. Fibrinogen was subnormal in three of the eight patients. The ethanol gelation test was negative in all patients. The 24 hours clotlysis was positive in one out of eight and serum FDP levels were slightly to markedly elevated in all patients examined.

TABLE 1

BLOOD COAGULATION TESTS IN GROUP I, ADMISSION DATA*

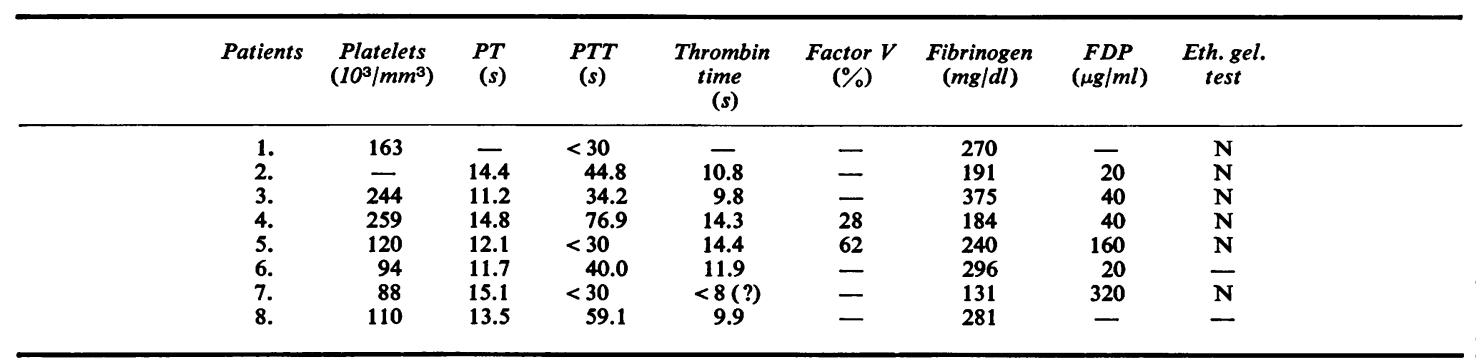

* Normal ranges of coagulation tests : platelet count $150-300.10^{3}$ per mm ${ }^{3}$, PT 11-13 s; PTT 35-48 s; thrombin time 9-11 s; fibrinogen $200-400 \mathrm{mg} / \mathrm{dl}$; factor V 70-120\%; factor VIII 70-120\%; serum FDP 0-10 $\mu \mathrm{g} / \mathrm{ml}$. N: negative.

TABLE 2

COAGULATION TESTS IN GROUP II: MEAN VALUES WITH STANDARD ERROR OF MEAN*

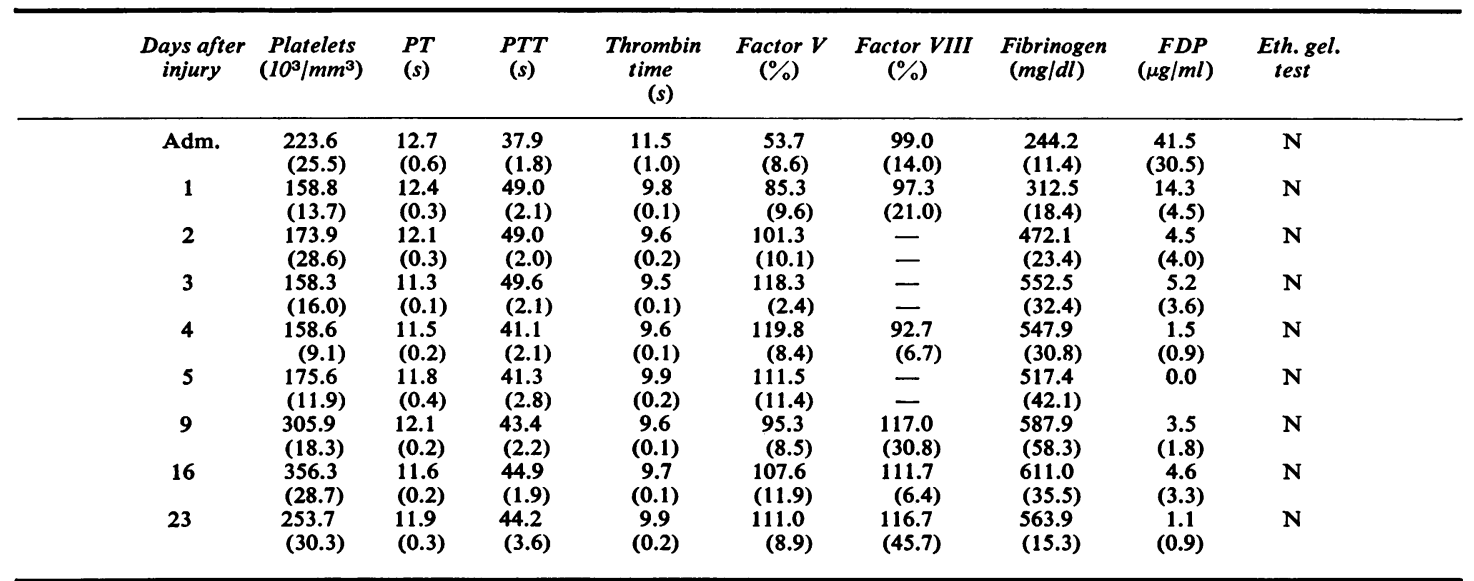

* For normal values see Table 1. 


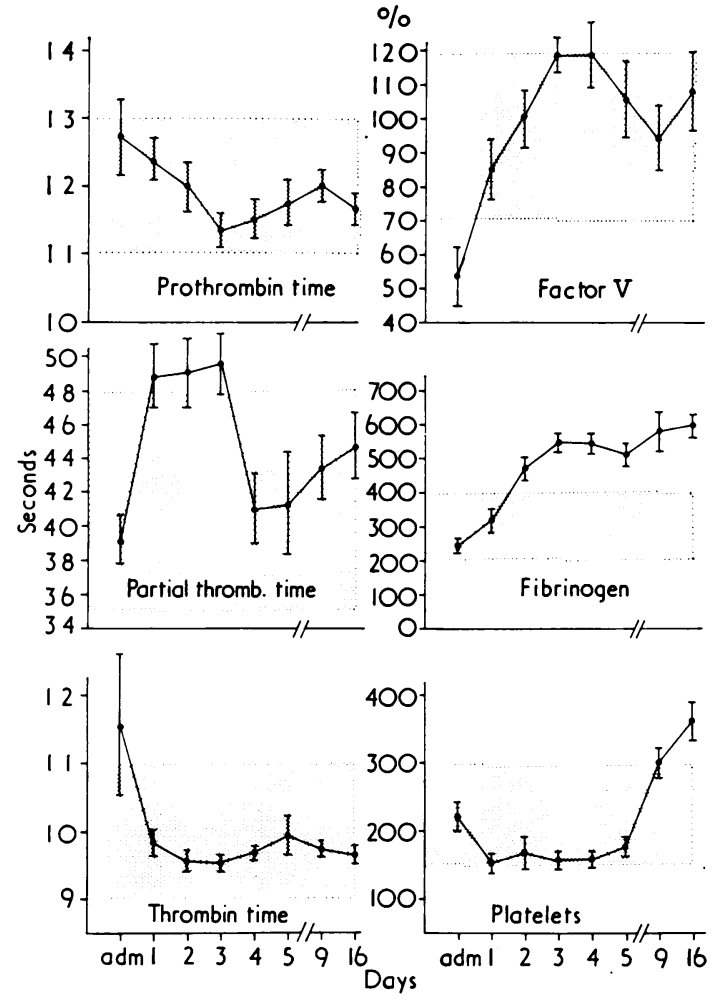

FIGURE Mean values ( \pm SEM) for six tests of patients in group II. Shaded areas represent normal values.
The results of group II (the patients with severe head injury) are shown in the Figure and Table 2. Platelet counts were normal at admission; on the following days borderline levels were present. The PT showed no abnormalities. The PTT was shortened at admission and significantly $(\mathrm{P}<0.001)$ lengthened thereafter on days 1,2 , and 3 . The thrombin time was slightly prolonged at admission. Levels of Factor $\mathrm{V}$ were lowered at admission. Factor VIII levels showed no abnormalities. Fibrinogen levels were normal and increased from day 1 on. Clotlysis was positive in three of nine patients at admission, in two of 14 patients at day 1 and negative in all patients thereafter. Serum FDP titres were moderately elevated in three of six patients at admission, slightly elevated in six of 12 at day 1 and one of 10 patients at day 2 . Thereafter slightly increased FDP levels were seen only occasionally. The ethanol gelation test was negative in all injured patients during the post-traumatic period.

The results of group III (the moderately injured patients) are shown in Table 3 . The same tendency of results is seen in this group compared with group II. However, the abnormalities in the moderately injured patients were less outstanding.

TABLE 3

COAGULATION TESTS IN GROUP III: MEAN VALUES WITH STANDARD ERROR OF MEAN*

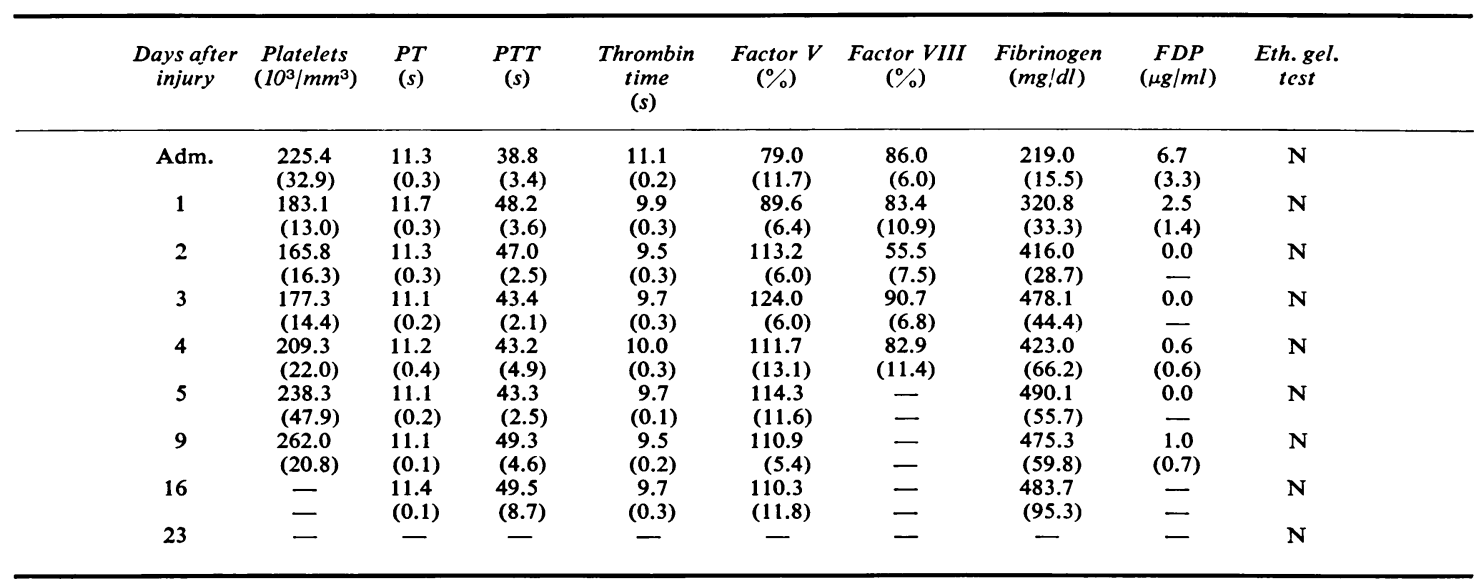

* For normal values see Table 1. 
Renal insufficiency or a bleeding tendency was never seen in these patients.

\section{DISCUSSION}

The diagnosis and laboratory findings of disseminated intravascular coagulation are still a topic of interest and discussion.

To avoid confusion of ideas, we mean by DIC a pathological process in which circulating fibrinogen is converted into circulating fibrin (Van Doorm et al., 1972). The fibrinogen-fibrin conversion may result in a deficiency of coagulation factors and platelets. Bowie et al. (1973) and McKay (1973) make a distinction between acute and chronic DIC. Acute DIC is defined as the classic clinical pattern with acute and alarming bleeding tendency and/or widespread intravascular clotting with predominantly oliguria. Laboratory findings are unmistakable: hypofibrinogenaemia, low coagulation factor levels, and lengthened screening tests with secondary activation of the fibrinolytic system and thrombocytopenia. The diagnosis of chronic DIC is much more sophisticated. It is presumed that a mild clotting stimulus gives rise to a slight decrease of fibrinogen and other coagulation factor levels. This may be followed by a rebound to above-normal values when a second mild clotting episode occurs. Again a slight decrease may occur of coagulation factors but to normal or above-normal levels. So the process is repeated and continuing with factor levels fluctuating at above-normal values. For the diagnosis of chronic DIC, these elevated levels seem to be important. However, platelet counts tend to remain below normal (McKay, 1973). In addition, increased serum FDP levels and soluble fibrin monomer complexes (SFMC) are found in this condition (Colman et al., 1972). For detection of clottable SFMC the ethanol gelation test is pertinent (Godal and Abildgaard, 1966). This test is more reliable for detecting DIC than the plasma protamine paracoagulation test (Seaman, 1970), which becomes positive in the presence of fibrin degradation products. For the detection of the chronic form of DIC the ethanol gelation test has proved to be of value (Kierulf and Godal, 1971), in spite of the fact that this test can become negative due to an intensive activation of fibrinolysis (Gerrits et al., 1974).
In our series we found no evidence favouring a state of acute DIC after head injury. At first sight the coagulation status of these patients seemed to show a picture of activated clotting at admission followed by signs of chronic DIC thereafter, with elevated fibrinogen levels and the presence of serum FDP. However, a positive ethanol gelation test was never observed during the post-traumatic period and elevated FDP levels disappeared after two days. Therefore we conclude that, at admission, a state of activated coagulation is indeed present, as is indicated, for example, by a shortened kaolin-activated PTT, and that chronic DIC after head injury is not present in these series. It seems probable that the activated state of coagulation is induced by thromboplastic material released from brain tissue into the systemic circulation, as many have suggested (Bang and McDowell, 1966; Keimowitz and Annis, 1973; Preston et al., 1974). Mostly our findings parallel those of Innes and Sevitt (1964) who found the same pattern after severe injury, without necessarily head or brain involvement. They described this as an 'early hypercoagulability' state.

Goodnight et al. (1974) described in their series the presence of (non-acute) defibrination (synonym used for DIC) in 13 patients with head trauma with brain tissue destruction, of whom three survived. This group is comparable with our group I and probably in most cases also with group II. They showed the same haemostatic abnormalities with the exception of fibrinogen levels and platelet counts which were higher in our series. In group III we found largely the same results as Goodnight et al. (1974) in a group of patients without clinical evidence of destruction of brain tissue. A support for their diagnosis of defibrination was the positivity of the plasma protamine test. This can be explained by the presence of serum FDP in their series, which also occurred in our patients. For severely head injured patients with defibrination, they suggested replacement therapy with cryoprecipitate, fresh-frozen plasma or platelet concentrates. Until haemostatic abnormalities after brain injury are clearly indentified, we think it is premature to give treatment with plasma constituents. For the present, this therapy should be restricted to a threatening and well-defined bleeding tendency. 
In all patients of groups I, II, and III we never observed abnormal bleeding. The initial haemostatic abnormalities were moderate even in those of group I (died because of brain injury), and returned rather quickly to normal in all others without supplementation therapy. In our opinion, neither acute nor chronic DIC seems to be a regular phenomenon in relation to severe head injury.

The authors wish to thank Mrs. J. Ophoff-Post, Miss B. Hansen, Miss R. Stienstra, and Miss W. Postma for their technical assistance and Miss G. A. Balstra for her assistance in typing.

\section{REFERENCES}

Bang, N. U., and McDowell, F. (1966). Cerebral infarction and blood clotting. Transactions of the American Neuro-, logical Association, 91, 84-86.

Bowie, E. J. W., Cooper, H. A., Fuster, V., Kazmier, F. J., and Owen, C. A., Jr., (1973). The diagnosis of intravascular coagulation. In Present Status of Thrombosis, pp. 137-143. Edited by R. Losito. Schattauer: Stuttgart.

Colman, R. W., Robboy, S. J., and Minna, J. D. (1972). Disseminated intravascular coagulation (DIC): an approach. American Journal of Medicine, 52, 679-689.

Doorm, J. M. van, Huisjes, H. J., and Smit Sibinga, C. T. (1972). Abruptio placentae, disseminated intravascular coagulation and the use of heparin: a must? Bibliotheca Anatomica, 12, 16-21.

Fontein, D. L. (1971). Voorspelling van de invloed van splenectomie op het verloop van de ziekte van Werlhof, p. 60 . Thesis. University of Groningen: Groningen.

Gerrits, W. B. J., Prakke, E. M., Meer, J. van der, and Vreeken, J. (1974). Causes of a negative ethanol gelation test in diffuse intravascular coagulation. Thrombosis et Diathesis Haemorrhagica, 31, 299-308.

Godal, H. C., and Abildgaard, U. (1966). Gelation of soluble fibrin in plasma by ethanol. Scandinavian Journal of Haematology, 3, 342-350.

Goodnight, S. H., Kenoyer, G., Rapaport, S. I., Patch, M. J. Lee, J. A., and Kurze, T. (1974). Defibrination after brain- tissue destruction. New England Journal of Medicine, 290, 1043-1047.

Hardisty, R. M., and MacPherson, J. C. (1962). A one-stage factor VIII (antihaemophilic globulin) assay and its use on venous and capillary plasma. Thrombosis et Diathesis Haemorrhagica, 7, 215-228.

Innes, D., and Sevitt, S. (1964). Coagulation and fibrinolysis in injured patients. Journal of Clinical Pathology, 17, 1-13.

Keimowitz, R. M., and Annis, B. L. (1973). Disseminated intravascular coagulation associated with massive brain injury. Journal of Neurosurgery, 39, 178-180.

Kierulf, P., and Godal, H. C. (1971). Fibrinemia in medical patients screened by the ethanol test. Acta Medica Scandinavica, 190, 185-190.

LeClerc, M., and Khodabandeh, A. (1953). Microméthode de dosage du fibrinogène plasmatique. Annales de Biologie Clinique, 11, 596-598.

McKay, D. G. (1973). Intravascular coagulation-acute and chronic-disseminated and local. In Coagulation, pp. 4572. Edited by G. Schmer and P. E. Strandjord. Academic Press: New York.

Merskey, C., Kleiner, G. J., and Johnson, A. J. (1966) Quantitative estimation of split products of fibrinogen in human serum, relation to diagnosis and treatment. Blood, 28, 1-18.

Preston, F. E., Malia, R. G., Sworn, M. J., Timperley, W. R., and Blackburn, E. K. (1974). Disseminated intravascular coagulation as a consequence of cerebral damage. Journal of Neurology, Neurosurgery, and Psychiatry, 37, 241-248.

Proctor, R. R., and Rapaport, S. I. (1961). The partial thromboplastin time with kaolin. American Journal of Clinical Pathology, 36, 212-219.

Quick, A. J. (1966). Hemorrhagic Diseases and Thrombosis, 2nd edn. p. 39. Lea and Febiger: Philadelphia.

Seaman, A. J. (1970). The recognition of intravascular clotting. The plasma protamine paracoagulation test. Archives of Internal Medicine, 125, 1016-1021.

Stormorken, H. (1957). The preparation of proaccelerin deficient (parahemophilia) plasma for the assay of proaccelerin. Scandinavian Journal of Clinical and Laboratory Investigation, 9, 273-276.

Vardi, Y., Streifler, M., Schujman, E., and Loewenthal, M. (1974). Diffuse intravascular clotting associated with a primary brain tumour. Journal of Neurology, Neurosurgery, and Psychiatry, 37, 987-990.

Vecht, C. J., and Smit Sibinga, C. T. (1974). Head injury and defibrination. Lancet, $2,905$.

Vermylen, C., and Verstraete, M. (1961). Antithrombin V: critical evaluation of its assessment and properties. Thrombosis et Diathesis Haemorrhagica, 5, 267-284. 